\title{
NOREPINEPHRINE INDUCED PULMONARY CONGESTION IN PATIENTS WITH AORTIC VALVE REGURGITATION *
}

\author{
By TIMOTHY J. REGAN, VALENTINO DEFAZIO, KENAN BINAK † AND \\ HARPER K. HELLEMS \\ (From the Cardiovascular Research Laboratories, Departments of Medicine, Wayne State Uni- \\ versity College of Medicine, and City of Detroit Receiving Hospital, \\ Detroit, Mich.)
}

(Submitted for publication March 3, 1959; accepted May 14, 1959)

The regulation of venous blood flow into the heart and the effects of blood volume redistribution upon cardiac function have not been amply defined. While enhanced venomotor tone induced by norepinephrine has been found to increase the volume of a central reservoir in the dog (1), such a volume shift has not been demonstrated in man, except inferentially by the finding of a decrease in the limb venous volume (2).

This type of alteration might be expected to affect cardiopulmonary hemodynamics, particularly in a situation where the volume of this central system has already been expanded. Such a state, exclusive of congestive failure, occurs to a notable degree in aortic regurgitation where deficient valve function fails to limit diastolic volume. Thus, a study of the response to norepinephrine in eight patients with this clinical state has been contrasted with the findings in seven normals.

\section{PATIENT MATERIAL}

Eight patients with isolated aortic regurgitation due to rheumatic fever, lacking clinical and hemodynamic evidence of mitral stenosis, were selected for this study. All had substantial left ventricular enlargement with the point of maximum apical impulse occurring in the sixth interspace, at, or within a few centimeters of, the anterior axillary line, while the electrocardiogram showed a left ventricular hypertrophy pattern in each instance. At the time of study, there were no symptoms or signs of heart failure, although three patients had had previous manifestations of decompensation and were subsequently well controlled on digitalis. Seven subjects were chosen for control studies. All had normal hearts by physical examination, X-ray and the electrocardiogram.

* This investigation was supported by Grant H-1492, National Heart Institute, National Institutes of Health, United States Public Health Service; Michigan Heart Association; and by the Receiving Hospital Research Corporation.

$\dagger$ Research Fellow. Rockefeller Foundation (19581959).

\section{METHODS}

All subjects were studied in the fasting state approximately two hours after receiving $0.1 \mathrm{Gm}$. of pentobarbital sodium. A double lumen catheter was used to measure pressures simultaneously from the pulmonary "capillary" and pulmonary artery. The "capillary" position was assumed to be present when the catheter could not be advanced farther in the lung bed, the tip did not move with the cardiac cycle and a compatible pressure pattern was obtained. A specimen of blood saturated with oxygen was secured from the wedged catheter tip whenever this was possible.

After serial oxygen consumptions showed constancy, $15 \mathrm{mg}$. of Evans blue dye was injected into the pulmonary artery and collected at two second intervals in a rotating fraction collector from a Cournand needle in the brachial artery. Total collection time was about $50 \mathrm{sec}-$ onds to accommodate the expected prolongation of the dye curve downslope, and was followed by a simultaneous recording of the systemic arterial, pulmonary arterial and "capillary" pressures with electrically integrated means.

An infusion of norepinephrine, $0.2 \mu \mathrm{g}$. per $\mathrm{Kg}$. of body weight per minute, was then begun through a polyethylene tube lying in the subclavian vein and continued for 15 minutes. The electrocardiogram and pressures from the pulmonary "capillary," pulmonary artery and brachial artery were recorded continuously. At 15 minutes, Evans blue dye was again injected. The effect of venous occlusion upon the norepinephrine response was assessed by repeating the infusion in four patients. Sphygmomanometer cuffs had been applied to three extremities at diastolic arterial pressure levels 15 minutes previously and maintained during the subsequent 15 minute infusion.

Since the assessment of the cardiac responsiveness to filling pressure and arterial pressure elevation requires information on the volume of blood which the contracting muscle ejects, the quantity partitioned into the forward and regurgitant flow must be ascertained. While the former is obtained with reasonable accuracy by the Hamilton method, the reliability of current methods for estimating regurgitation in man is not established. The method most thoroughly scrutinized is that devised by Korner and Shillingford (3).

The validity of this method of estimating regurgitant flow depends upon the thesis that the downslope of the descending limb of the indicator dilution curve is fixed for a given cardiac output and central volume. The pres- 
ence of valvular incompetence produces a decrease in the gradient of this downslope which is used as a measure of regurgitant flow.

Minor variations of this gradient have been observed between normal subjects with the same forward flow and central volume and place a limit on the accuracy of backflow quantification in a given patient (3). However, when sequential testing is performed, this inaccuracy is diminished $(4,5)$. While it is generally agreed that small valvular leaks are not reliably detected by this method (6), gross leakage, sufficient to be clinically certain, is usually detectable (5) and thus, the patients chosen were those who appeared to have a substantial, isolated, regurgitant lesion of the aortic valve. Moreover, the modification of this flow in the same model or patient may be fairly accurately detected, if sufficiently large, once one already has an indicator dilution curve for comparative purposes describing the particular system to be modified $(4,5)$. Since the slopes of the dye curve may allegedly be altered by inadequate flow rates to the fraction collector (7), it is pertinent to note that the volumes collected in the control state were above this minimal rate. As the collection volumes increased after norepinephrine, with and without tourniquets, any change in the dye curve slope would also not be ascribed to this factor. In addition, the qualitative contour of the curve has been found not significantly altered despite varied sampling volumes obtained through simultaneous determinations from the ear, radial and femoral arteries (8).

The calculation of the reciprocal of the slope predicted for a given cardiac output and central volume (Hamilton method) was derived from the Korner-Shillingford regression equation based on 91 indicator dilution curves: $\log 1 / \mathrm{s}=0.8766-0.0614$ (cardiac output) $+1.129 \log$ volume. In the absence of valvular insufficiency or shunts, these authors, based on studies in models and patients, claimed that $1 / \mathrm{s}$ is quite predictable. In a modification of the original method (6), the observed slope is calculated from the semilogarithmically plotted curve:

$$
1 / s=\frac{t_{2}-t_{1}}{\log c_{1}-\log c_{2}},
$$

where $t_{1}, c_{1}$, and $t_{2}, c_{2}$ represent the coordinates of two points on the straight line downslope. By setting $c_{1}$ and $c_{2}$ one logarithmic cycle apart, the denominator is reduced to 1 , and the value for the equation is equal to the duration of descent of the downslope to one-tenth of a given point along its course. Total cardiac output is then derived from the product of forward flow and the ratio $1 / \mathrm{s}$ (observed) $/ 1 / \mathrm{s}$ (predicted). The difference between the total and forward flows is attributed to regurgitant flow.

The most serious objection to this method has been raised by the finding that regurgitation into the narrow rigid proximal chamber of an experimental model may fail to distort the indicator dilution curve significantly from that occurring without valvular incompetence (9). Although such gross inaccuracy has not been reported in man or animal studies, this situation bears considera- tion in the interpretation of dilution curves. The chamber size and elasticity factors during the infusion of norepinephrine are, in all probability, opposite in direction to those associated with the large error alluded to above for the following reasons. Epinephrine in the dog has been shown with a cinefluorographic technique to increase the left ventricular diastolic area (10), and a similar change may be inferred for norepinephrine from the rise in left ventricular diastolic pressures associated with its use (11). Similar pressure changes occur in man, judged by left atrial mean pressures (12). Since the distensibility of the ventricle is increased by epinephrine (11), such pressure changes would imply a greater diastolic volume in the left ventricle.

The calculation of resistances to forward flow was done by accepted methods, as was the total left ventricular stroke work, with a correction for the contribution of filling pressure to the calculated ventricular work (13). Statistical significance was appraised by the Fischer " $t$ " test method (14).

Since none of the patients selected had mitral stenosis, the use of the pulmonary "capillary" mean pressure as a measure of the filling pressure of the left ventricle appears justified: first of all by its close correspondence to the left atrial mean pressures in man (15); and secondly, by a sufficiently close correlation of this latter parameter with the end-diastolic pressure of the left ventricle to minimize inaccuracy in the interpretation of the relation of filling pressure to stroke work (16). Direct measurement of the force of ventricular contraction, showing a linear relationship with calculated stroke work during the changes induced by norepinephrine, justifies the use of this parameter as a measure of contractility (17).

Calculation of the transaortic valvular pressure difference throughout diastole was not feasible in the absence, in nearly all instances, of a suitable dicrotic notch in the brachial arterial curve to indicate the onset of diastole. Left ventricular pressure curves, not warranted in these patients, would constitute the only means of timing the diastolic phase precisely. Thus, we have employed the end-diastolic systemic arterial pressure in the control period and during norepinephrine infusion, comparing them with their respective pulmonary "capillary" pressures, as an indication of the relative change in the transaortic valvular diastolic pressure difference.

\section{RESULTS}

Unusual reactions to the infusion of norepinephrine were not encountered except for a brief episode of sinus arrhythmia in one patient and the transient occurrence of ventricular extrasystoles in another, both occurring early and disappearing some minutes before the injection of Evans blue dye.

As detailed in Tables I and II, a tendency for a decline in cardiac output and increase in central volume was noted in both groups, but in an in- 
TABLE I

Hemodynamic response to norepinephrine in seven normal patients

\begin{tabular}{|c|c|c|c|c|c|c|c|c|c|c|}
\hline \multirow{2}{*}{$\begin{array}{c}\text { Patient, } \\
\text { Age, } \\
\text { Race, Sex, } \\
\text { B.S.A./M.2 }\end{array}$} & \multirow[b]{2}{*}{ Time } & \multirow[b]{2}{*}{$\begin{array}{l}\text { Cardiac } \\
\text { output }\end{array}$} & \multirow[b]{2}{*}{$\begin{array}{l}\text { Central } \\
\text { volume }\end{array}$} & \multirow[b]{2}{*}{$\begin{array}{c}\text { Pulse } \\
\text { per } \\
\text { min. }\end{array}$} & \multirow{2}{*}{$\begin{array}{c}\text { Left } \\
\text { ventricular } \\
\text { stroke } \\
\text { work }\end{array}$} & \multicolumn{3}{|c|}{ Mean pressures } & \multicolumn{2}{|c|}{ Resistances } \\
\hline & & & & & & $\begin{array}{c}\text { Brachial } \\
\text { artery }\end{array}$ & $\begin{array}{c}\text { Pulmonary } \\
\text { artery }\end{array}$ & $\begin{array}{l}\text { Pulmonary } \\
\text { "capillary" }\end{array}$ & $\begin{array}{c}\text { Peripheral } \\
\text { arterial }\end{array}$ & $\begin{array}{c}\text { Pulmonary } \\
\text { arteriolar }\end{array}$ \\
\hline \multirow{3}{*}{$\begin{array}{l}\text { E. S. } \\
41,{ }_{N F} \\
1.57\end{array}$} & $\min$ & L./min. & $L$. & & $\underset{\text { beat } / M .}{\operatorname{Gm} .}$ & & $m m . H g$ & & \multicolumn{2}{|c|}{ dynes-sec.-cm. ${ }^{-8}$} \\
\hline & $0^{*}$ & 5.39 & 1.54 & 70 & 46.1 & 80 & & & 1,187 & \\
\hline & 15 & 4.67 & 2.15 & 60 & 60.0 & 100 & & & 1,716 & \\
\hline \multirow{2}{*}{$\begin{array}{l}\text { M. S. } \\
38, W F \\
1.53\end{array}$} & 0 & 4.35 & 1.64 & 80 & 47.5 & 103 & 13 & 5 & 1,893 & 147 \\
\hline & 15 & 3.78 & 1.56 & 71 & 55.0 & 125 & 29 & 9 & 2,645 & 445 \\
\hline \multirow{2}{*}{$\begin{array}{l}\text { N. S. } \\
36, \text { WM } \\
1.88\end{array}$} & 0 & 8.69 & 1.94 & 85 & 62.7 & 90 & 15 & 6 & 827 & 83 \\
\hline & 15 & 7.45 & 2.07 & 72 & 99.3 & 146 & 29 & 14 & 1,556 & 128 \\
\hline \multirow{2}{*}{$\begin{array}{l}\mathrm{J} . \mathrm{M} . \\
41, \mathrm{NM} \\
1.65\end{array}$} & 0 & 5.67 & 2.45 & 71 & 56.1 & 90 & & & 1,262 & \\
\hline & 15 & 5.69 & 2.76 & 64 & 105.4 & 155 & & & 2,173 & \\
\hline \multirow{2}{*}{$\begin{array}{l}\text { H. N. } \\
34, \mathrm{NF} \\
1.68\end{array}$} & 0 & 7.80 & 1.70 & 87 & 55.9 & 85 & 15 & 7 & 871 & 82 \\
\hline & 15 & 7.82 & 1.82 & 87 & 93.0 & 142 & 26 & 14 & 1,455 & 123 \\
\hline \multirow{2}{*}{$\begin{array}{l}\mathrm{J} . \mathrm{G} . \\
25, \mathrm{NM} \\
1.58\end{array}$} & 0 & $4.34 \dagger$ & & 65 & 44.7 & 84 & 11 & 6 & 1,554 & 93 \\
\hline & 15 & 3.19 & & 48 & 49.2 & 97 & 20 & 11 & 2,438 & 226 \\
\hline \multirow{2}{*}{$\begin{array}{l}\text { S. D. } \\
31, \text { WM } \\
1.61\end{array}$} & 0 & 4.76 & 1.66 & 73 & 52.2 & 95 & 11 & 5 & 1,602 & 102 \\
\hline & 15 & 4.62 & 1.77 & 67 & 94.4 & 162 & 15 & 9 & 2,802 & 104 \\
\hline $\begin{array}{l}\text { Mean } \\
\text { values }\end{array}$ & $\begin{array}{r}0 \\
15\end{array}$ & $\begin{array}{l}5.86 \\
5.32 \ddagger\end{array}$ & $\begin{array}{l}1.82 \\
2.02 \ddagger\end{array}$ & $\begin{array}{l}75.9 \\
67\end{array}$ & $\begin{array}{l}52.1 \\
79.4\end{array}$ & $\begin{array}{r}89.6 \\
132.4\end{array}$ & $\begin{array}{l}13 \\
24\end{array}$ & $\begin{array}{r}6 \\
11\end{array}$ & $\begin{array}{l}1,314 \\
2,112\end{array}$ & $\begin{array}{l}101.4 \\
205.2\end{array}$ \\
\hline $\mathbf{p}$ & & & & $<0.001$ & $<0.001$ & $<0.001$ & $<0.01$ & $<0.01$ & $<0.001$ & $<0.01$ \\
\hline
\end{tabular}

* Control period.

† Fick cardiac output.

$\ddagger$ No significant difference from control period.

consistent manner. The significant bradycardia encountered in normals was not paralleled in aortic insufficiency. That substantial flow leaks occurred in the patients with aortic insufficiency is attested by the finding of a mean regurgitation, 61 per cent of the aortic outflow. In the normal group, no significant leak was exhibited. The infusion of norepinephrine was attended by a significant reduction of the calculated regurgitation, contributing to the finding of a decline in the total flow. Since some leak probably occurs across the mitral valve in most enlarged left ventricles, an anticipated accentuation with norepinephrine would not qualitatively modify the observed findings (12).

In striking contrast to the $5 \mathrm{~mm}$. $\mathrm{Hg}$ rise in the pulmonary "capillary" pressure for the normal group, was the rise from $8 \mathrm{~mm}$. $\mathrm{Hg}$ to $29 \mathrm{~mm}$. $\mathrm{Hg}$ in those with aortic regurgitation. The major part of this change occurred after five minutes of norepinephrine infusion and was usually complete by 10 minutes. As this increment exceeded that of the brachial artery diastolic pressure (mean $4 \mathrm{~mm}$. $\mathrm{Hg}$ ) wherever the regurgitant flow was diminished, a decline in the aortic-ventricular diastolic pressure difference could account for this flow change. The one patient (A. W.) with the smallest control regurgitant volume exhibited an increase in leak associated with a rise in this pressure difference.

Whereas the small increment in the filling pressure was associated with a substantial rise in the 
NOREPINEPHRINE INDUCED PULMONARY CONGESTION

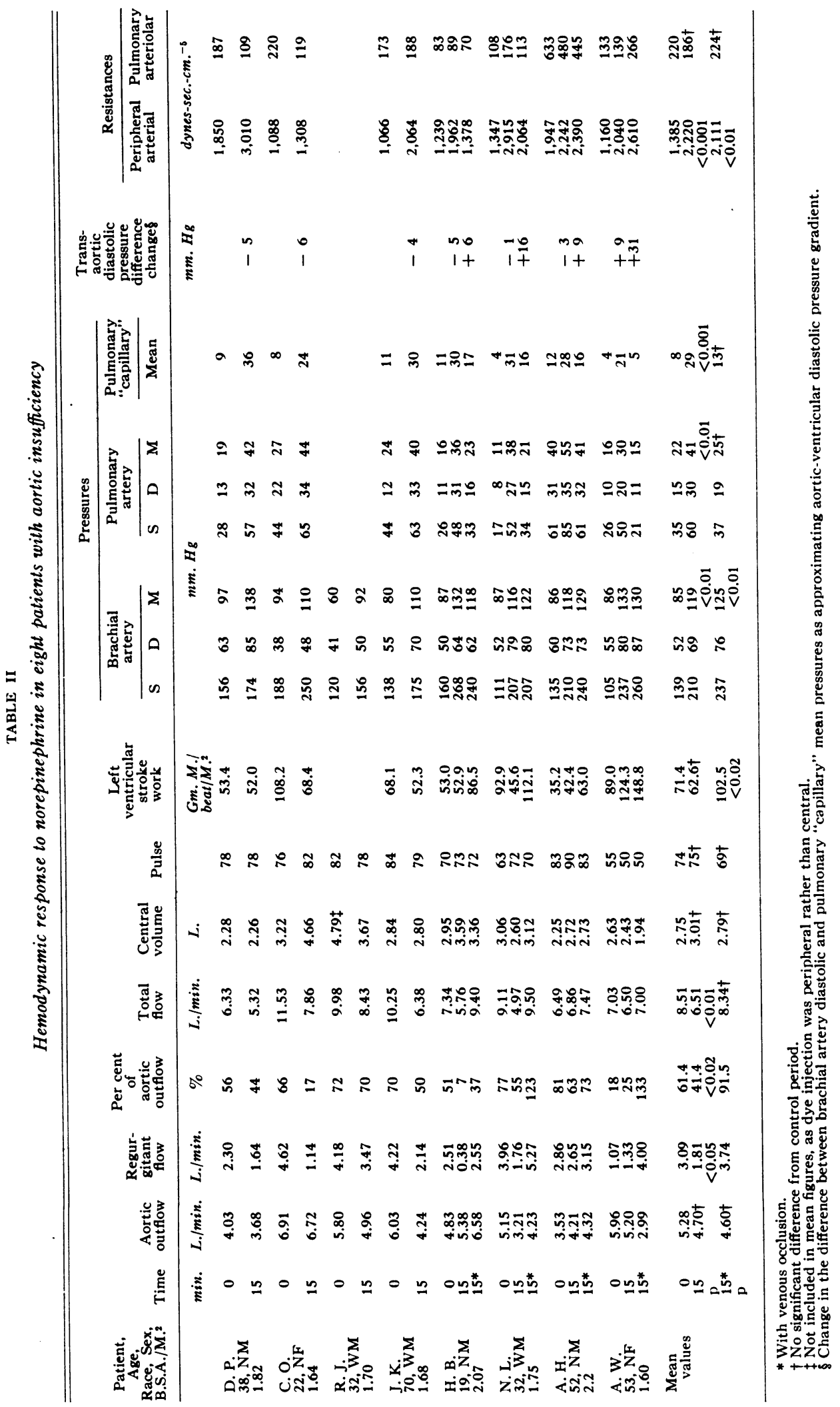




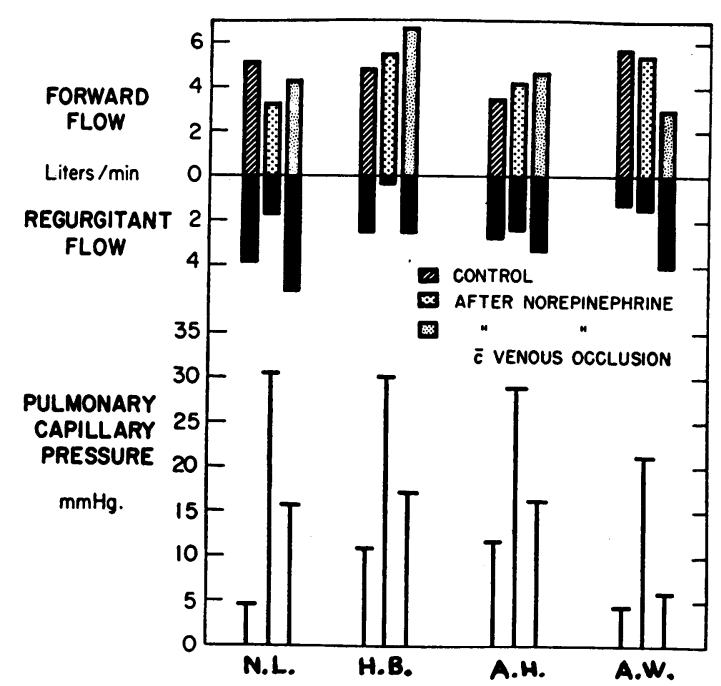

Fig. 1. Effects of Venous Occlusion upon Action OF NOREPINEPHRINE

The vertical lines designating pulmonary "capillary" pressure correspond in time to the flow column immediately above.

left ventricular stroke work for the normals, the nearly fourfold pressure rise in the presence of aortic regurgitation involved no higher left ventricular performance level. In an effort to determine whether the response of the pathologic heart could be attributed to volume displacement from the periphery, tourniquets were applied to the extremities of four patients. In these circumstances, as detailed in Table II and Figure 1, the $5 \mathrm{~mm}$. $\mathrm{Hg}$ mean rise in the pulmonary "capillary" pressure after norepinephrine corresponded to the finding in normals, as did the substantial increment in the left ventricular stroke work. Thus, hydrostatic pressure levels usually associated with pulmonary edema were effectively prevented by restricting the redistributive ability of the venous system. The increase in the aortic-ventricular diastolic pressure gradient was associated with restoration of regurgitant volumes to control or higher values, confirming the known relationship of transvalvular diastolic pressure difference to regurgitant flow (18).

Although the calculated vascular resistances clearly became elevated in both the total peripheral arterial and pulmonary arteriolar beds in the normal, a change in the latter parameter failed to occur in the valvular insufficiency group after norepinephrine. In a more direct experimental ap- proach, elevation of left atrial pressure has tended to lower resistance in the pulmonary bed (19). Presumably a similar situation has occurred here, with the pulmonary "capillary" reflecting left atrial pressures. As hematocrit changes may affect viscosity and thus alter resistance, it is of note that the hematocrit rose an inconsequential 1 per cent in both groups.

\section{DISCUSSION}

The finding of a significant rise in pulmonary "capillary" pressures after norepinephrine in the normal human subject has been ascribed to increases in left atrial pressure (20). Direct evidence supporting this contention has been obtained through left heart catheterization where slight elevations of mean atrial pressures in normals, and substantial rises in pathologic hearts have been observed (21), that are quite comparable to the striking increments of pulmonary "capillary" pressure found in this group with aortic regurgitation. Since pulmonary vein constriction would appear eliminated as a major pathogenetic factor, a direct myocardial depressant effect or displacement of blood from the periphery remain as potential mechanisms. Several sources of evidence would indicate the latter as most probable.

Such a volume shift has been observed in the dog after norepinephrine with an increase in directly measured venous return (15) and in the volume of a reservoir placed distal to the left auricle (1). The cardiopulmonary location of this blood has been further evidenced by increased Hamilton central volumes and left ventricular enddiastolic pressure (11). That a translocation of blood from the periphery is involved in this process would appear to be the case, since limb volumes measured plethysmographically indicate a decline $(2,22)$.

From the foregoing data one would have expected to find an increase in the calculated central volume. The magnitude of the change observed does not itself confirm a significant central shift of blood. However, the technique of measurement here used does not provide absolute quantification since it fails to account for volumes of blood not displaced by the flow process (23).

A similar disparity has been found in patients with mitral stenosis where no significant increase in calculated pulmonary blood volume occurred 
in spite of high pulmonary vascular pressures (24). Moreover, the presence of a methodical error of 15 per cent (25) would indicate that a shift of $400 \mathrm{ml}$. may escape detection. A rapid increment of this size, in the presence of an already expanded volume, may affect the pressure-volume relationship of the left atrium and pulmonary artery sufficiently to give pulmonary pressures of the order observed, since the shape of the curve describing this relationship is such that the pressure rise exceeds volume increments above an illdefined limit (26). It may also be noted that others have failed to find a significant volume increment after epinephrine in humans at dosage levels inducing a rise in cardiac output (27), despite the fact that this cardiac effect is largely dependent upon greater venous return (28). Further, the fact that the striking changes in pulmonary "capillary" pressure were prevented by trapping blood volume in the extremities would support the thesis that the pressure rise after norepinephrine was due to volume displacement, despite the failure to find significant expansion of the calculated central volume.

As the directional change of the total output and work of the heart with an incompetent aortic valve showed a decline in the face of elevated filling pressures, these findings correspond to those occurring in low output heart failure (29). The inability of this dilated, hypertrophied myocardium to respond normally to the effects of norepinephrine with an increase in stroke work may be attributable in part, at least, to the dual demands imposed by an increased inflow load and outflow resistance. Interference with the venous return modifies this situation sufficiently to enable a contractility response indistinguishable from that occurring in the normal, presumably by avoiding excessive distention of the ventricle. This further verifies the similarity of this state of norepinephrine induced pulmonary congestion to low output heart failure where an enhanced performance of the myocardium also follows venous occlusion (30). Whether interference with outflow resistance alone would similarly affect the cardiac response is problematic.

In evaluating the response of the cardiac output in this experimental situation, the major source of error resides in the estimation of the regurgitant volume. Since this segment of the total cardiac output would, of necessity, be disproportionately increased for a suitable cardiac response to occur at these filling pressure levels $(16,29)$, it is difficult to gainsay the conclusion that myocardial performance has been compromised. This represents a relatively severe depression of the ventricular function curve, as it is usually shifted to a higher level by virtue of the direct myocardial activity of most sympathomimetics (31).

While this study illustrates an inappropriate translocation of blood in the presence of a defective, though compensated myocardium, this activity may actually contribute to the effectiveness of norepinephrine in shock states (32). Conversely, the peripheral venoconstriction present in low output heart failure (33) would tend to aggravate pulmonary congestion unless moderated by methods of reducing venous return.

\section{SUMMARY}

To assess the pluripotential effects of norepinephrine on the cardiovascular system of man, the response in the normal has been contrasted with that occurring in eight compensated patients with aortic valve regurgitation. Indicator dilution curves were obtained before and during the norepinephrine infusion $(0.2 \mu \mathrm{g}$. per $\mathrm{Kg}$. per minute) to evaluate the cardiac output, regurgitant flow and central volume. Intravascular pressures from the pulmonary "capillary," pulmonary artery and brachial artery were recorded during the procedure.

A disparity of response between the two groups was most manifest in the pulmonary "capillary" and artery pressure alterations, a nearly fourfold rise to pulmonary congestion levels in the aortic regurgitation group contrasted with a $5 \mathrm{~mm} . \mathrm{Hg}$ mean rise occurring in the normal. Whereas this small increment of left ventricular filling pressure was associated with a sizable stroke work increase in the normal, no significant change in contractility was found in the aortic regurgitant group, despite markedly elevated filling pressures. Bradycardia and increased pulmonary arteriolar resistance, present in the normals, were also absent in this group.

A consideration of the pathogenetic factors contributing to this situation suggested that displacement of blood from the peripheral venous system 
was the predominant, if not sole, mechanism in the induction of pulmonary congestion and diminished left ventricular performance in this circumstance. This interpretation received indirect support from data acquired in four patients during peripheral venous occlusion by tourniquet. Here, the pulmonary "capillary" pressure increment and the stroke work response after norepinephrine were of the same order exhibited in the normal.

A relationship of regurgitation to the aorticventricular diastolic pressure difference is inferred from the observation that whenever the pulmonary "capillary" pressure rise exceeded the systemic diastolic arterial response, the calculated regurgitant volume diminished, while this volume was usually increased when the converse pressure relationship existed.

\section{ACKNOWLEDGMENT}

Acknowledgment is made of the technical assistance rendered by Miss Virginia Everett and Miss Margaret Reese, and the secretarial services of Mrs. Shirley Loy.

\section{REFERENCES}

1. Rose, J. C., and Fries, E. D. Alterations in systemic vascular volume of the $\operatorname{dog}$ in response to hexamethonium and norepinephrine. Amer. J. Physiol. 1957, 191, 283.

2. Eckstein, J. W., and Hamilton, W. K. The pressurevolume responses of human forearm veins during epinephrine and norepinephrine infusions. J. clin. Invest. 1957, 36, 1663.

3. Korner, P. I., and Shillingford, J. P. The quantitative estimation of valvular incompetence by dye dilution curves. Clin. Sci. 1955, 14, 553.

4. Korner, P. I., and Shillingford, J. P. Further observations on the estimation of valvular incompetence from indicator dilution curves. Clin. Sci. 1956, 15, 417.

5. Eich, R. H., Staib, I., Enerson, D. M., and Brown, H. An experimental evaluation of the indicator-dilution technique for the detection of mitral regurgitation. Clin. Res. 1958, 6, 217.

6. Novack, P., and Schlant, R. C. Korner-Shillingford method for estimating regurgitant flow. Meth. med. Res. 1958, 7, 76.

7. Lacy, W. W., Emanuel, R. W., and Newman, E. V. Effect of the sampling system on the shape of indicator dilution curves. Circulat. Res. 1957, 5, 568.

8. Beard, E. F., Wood, E. H., and Clagett, O. T. Study of hemodynamics in coarctation of the aorta using dye dilution and direct intra-arterial pressure recording methods. J. Lab. clin. Med. 1951, 38, 858.
9. Hoffman, J. I. E., and Rowe, G. G. Some factors affecting indicator dilution curves in the presence and absence of valvular incompetence. $\mathrm{J}$. clin. Invest. 1959, 38, 138.

10. Rushmer, R. F., and Thal, N. Factors influencing stroke volume: A cinefluorographic study of angiocardiography. Amer. J. Physiol. 1952, 163, 509.

11. Shadle, O. W., Moore, J. C., and Billig, D. M. Effect of 1-Arterenol infusion on "central blood volume" in the dog. Circulat. Res. 1955, 3, 385.

12. Braunwald, E., Welch, G. H., Jr., and Morrow, A. G. The effects of acutely increased systemic resistance on the left atrial pressure pulse: A method for the clinical detection of mitral insufficiency. J. clin. Invest. 1958, 37, 35.

13. Warren, J. V., and Gorlin, R. Calculation of vascular resistance. Meth. med. Res. 1958, 7, 98.

14. Batson, H. C. Statistical methods in medical research in Notes on Medical Basic Sciences Course. Washington, D. C., Army Medical Service Graduate School, 1951-53, vol. 3, p. 371.

15. Connolly, D. C., Kirklin, J. W., and Wood, E. H. The relationship between pulmonary artery wedge pressure and left atrial pressure in man. Circulat. Res. 1954, 2, 434.

16. Sarnoff, S. T. Myocardial contractility as described by ventricular function curves: Observations on Starling's law of the heart. Physiol. Rev. 1955, 35, 107.

17. Cotten, M. DeV., and Maling, H. M. Relationships among stroke work, contractile force and fiber length during changes in ventricular function. Amer. J. Physiol. 1957, 189, 580.

18. Wiggers, C. J. Circulatory Dynamics; Physiologic Studies. New York, Grune and Stratton, 1952.

19. Borst, H. G., McGregor, M., Whittenberger, J. L., and Berglund, E. Influence of pulmonary arterial and left atrial pressures on pulmonary vascular resistance. Circulat. Res. 1956, 4, 393.

20. Fowler, N. O., Westcott, R. N., Scott, R. C., and McGuire, J. The effect of nor-epinephrine upon pulmonary arteriolar resistance in man. J. clin. Invest. 1951, 30, 517.

21. Rashkind, W. J., Lewis, D. H., Henderson, J. B., Heiman, D. F., and Dietrick, R. B. Venous return as affected by cardiac output and total peripheral resistance. Amer. J. Physiol. 1953, 175, 415.

22. Shadle, O. W., Zukof, M., and Diana, J. Translocation of blood from the isolated dog's hindlimb during levarterenol infusion and sciatic nerve stimulation. Circulat. Res. 1958, 6, 326.

23. Dow, P. Estimations of cardiac output and central blood volume by dye dilution. Physiol. Rev. 1956, 36, 77.

24. Borden, C. W., Ebert, R. V., Wilson, R. H., and Wills, H. S. Studies of the pulmonary circulation. II. The circulation time from the pulmonary artery to the femoral artery and the quantity of blood in the lungs in patients with mitral stenosis and 
in patients with left ventricular failure. J. clin. Invest. 1949, 28, 1138.

25. Cournand, A. F. Pulmonary circulation. Its control in man, with some remarks on methodology. Amer. Heart J. 1957, 54, 172.

26. Sarnoff, S. J., and Berglund, E. Pressure-volume characteristics and stress relaxation in the pulmonary vascular bed of the dog. Amer. J. Physiol. 1952, 171, 238.

27. Doyle, J. T., Wilson, J. S., Lepine, C., and Warren, $J$. An evaluation of the measurement of the cardiac output and of the so-called pulmonary blood volume by the dye-dilution method. J. Lab. clin. Med. 1953, 41, 29.

28. Guyton, A. C., Lindsey, A. W., Abernathy, B., and Langston, J. B. Mechanism of the increased venous return and cardiac output caused by epinephrine. Amer. J. Physiol. 1958, 192, 126.

29. Lewis, B. M., Houssay, H. E. J., Haynes, F. W., and Dexter, L. The dynamics of both right and left ventricles at rest and during exercise in patients with heart failure. Circulat. Res. 1953, 1, 312.

30. Judson, W. E., Hollander, W., Hatcher, J. D., Halperin, M. H., and Friedman, I. H. The cardiohemodynamic effects of venous congestion of the legs or of phlebotomy in patients with and without congestive heart failure. J. clin. Invest. 1955, 34, 614.

31. Welch, G. H., Jr., Braunwald, E., Case, R. B., and Sarnoff, S. J. The effect of mephentermine sulfate on myocardial oxygen consumption, myocardial efficiency and peripheral vascular resistance. Amer. J. Med. 1958, 24, 871.

32. Gilmore, J. P., Smythe, C. M., and Handford, S. W. The effect of 1-norepinephrine on cardiac output in the anesthetized dog during graded hemorrhage. J. clin. Invest. 1954, 33, 884.

33. Wood, J. E., Litter, J., and Wilkins, R. W. Peripheral venoconstriction in human congestive heart failure. Circulation 1956, 13, 524. 